\title{
Germinação, vigor e sanidade de sementes de fava d'anta (Dimorphandra mollis Benth.) obtidas de frutos coletados no solo e na planta
}

\author{
ARAUJO, A.V.; ; SALES, N.L.P.; FERREIRA, I.C.P.V.; BRANDÃO JUNIOR, D.; MARTINS, E.R. \\ Instituto de Ciências Agrárias, Universidade Federal de Minas Gerais - Caixa Postal 135 - CEP 39.404-006 - \\ Montes Claros, MG; *viniciusnca@yahoo.com.br.
}

\begin{abstract}
RESUMO: O objetivo do trabalho foi avaliar a qualidade fisiológica e sanitária das sementes obtidas a partir de frutos maduros coletados no solo e nas plantas de fava d'anta, espécie medicinal nativa do Cerrado, ameaçada de extinção, cujos frutos são ricos em rutina. O delineamento experimental empregado foi o inteiramente casualizado, com 10 repetições. Cada repetição foi constituída de uma caixa gerbox contendo 15 sementes cada. A qualidade fisiológica foi determinada por meio de testes de germinação e vigor, avaliando-se a porcentagem de germinação, o índice de velocidade de germinação (IVG) e a massa seca das raízes primárias. A qualidade sanitária foi determinada pela identificação dos microorganismos patogênicos associados às sementes, bem como pela porcentagem de ocorrência destes em cada parcela. Os fungos identificados nas sementes pertencem aos gêneros Fusarium, Alternaria, Aspergillus, Cladosporium, Colletrotrichum, Helminthosporium, Nigrospora, Penicillum, Phoma e Phomopsis. Sementes oriundas de frutos coletados no solo foram mais contaminadas por agentes patogênicos e apresentaram germinação $(56,67 \%)$, vigor e sanidade inferiores às sementes obtidas de frutos coletados na planta.
\end{abstract}

Palavras-chave: qualidade fisiológica e sanitária, plantas medicinais, Fusarium, Cladosporium

\begin{abstract}
Germination, vigor and sanity of "fava d'anta" (Dimorphandra mollis Benth.) seeds obtained from fruits collected both in the soil and in the plant. The aim of this work was to evaluate the physiological and sanitary quality of seeds obtained from mature fruits collected in the soil and in "fava d'anta" plants. Dimorphandra mollis constitutes an endangered medicinal species native to cerrado and presents fruits rich in rutin. The experimental design was completely randomized, with 10 replicates. Each replicate consisted of a gerbox containing 15 seeds each. Physiological quality was assessed through germination and vigor tests by evaluating germination percentage, germination velocity index (GVI), and primary root dry matter. Sanitary quality was evaluated by identifying pathogenic microorganisms associated with the seeds, as well as their occurrence percentage in each plot. The identified fungi belonged to the genera Fusarium, Alternaria, Aspergillus, Cladosporium, Colletotrichum, Helminthosporium, Nigrospora, Penicillium, Phoma and Phomopsis. Seeds from fruits collected in the soil were more contaminated by pathogenic agents and presented lower germination $(56.67 \%)$, vigor and health than seeds from fruits collected in the plant.
\end{abstract}

Key words: physiological and sanitary quality, medicinal plants, Fusarium, Cladosporium

\section{INTRODUÇÃO}

O Cerrado do Norte de Minas Gerais se encontra bastante degradado em conseqüência de diversos fatores. Dentre eles estão o desmatamento para a produção de carvão, abertura de fronteiras agrícolas, mineração, atividades florestais e exploração de espécies nativas para fins medicinais, sem orientação técnica, causando a redução da diversidade de espécies e do número de indivíduos das espécies remanescentes.

De acordo com Silva (1986), com a expansão da fronteira agrícola nas regiões de Cerrado, muitas espécies arbóreas encontram-se ameaçadas de

Recebido para publicação em 28/04/2008

Aceito para publicação em 24/10/2008

Rev. Bras. PI. Med., Botucatu, v.11, n.2, p.170-175, 2009. 
extinção, dentre elas, a fava d'anta, devido a sua forma de exploração, que é normalmente extrativista.

A fava d'anta ou favela (Dimorphandra mollis Benth.), pertencente à família Leguminosae é planta típica do Cerrado brasileiro e tem grande importância socioeconômica em algumas regiões compreendidas neste bioma. Seu uso é vasto (desde a madeira para confecções de móveis até a casca rica em tanino), porém o principal uso é a extração da rutina, tonificador das artérias do coração, além de combater os radicais livres. A multiplicação dessa planta, até o momento, tem sido feita apenas por sementes (Lorenzi \& Matos, 2002).

A freqüência da contaminação fúngica das sementes de essências florestais, especialmente as das plantas nativas, é explicada por Ferreira (1989), como conseqüência de características próprias dos frutos, que abrigam as sementes e do processo como as sementes são coletadas, beneficiadas e armazenadas. De acordo com este autor, normalmente na colheita de sementes já se têm frutos abertos, onde parte de suas sementes recebem contaminações fúngicas via vento, chuva e insetos. O mesmo autor também cita que, devido à inacessibilidade dos frutos em árvores de porte muito elevados, a colheita de sementes é efetuada a partir de frutos ou mesmo sementes caídas no chão. No solo, sob as árvores, parte dos frutos e sementes é colonizada por fungos diversos.

As sementes de fava d'anta são portadoras de microrganismos que interferem na germinação e causam a morte das mesmas (Giuliano et al., 2005). Estes autores também citam que há uma taxa elevada de sementes contaminadas, que morrem logo após a germinação.

Desta forma, o presente trabalho foi desenvolvido visando avaliar a qualidade fisiológica e sanitária das sementes obtidas a partir de frutos maduros coletados no chão e nas plantas de fava d'anta.

\section{MATERIAL E MÉTODO}

Os experimentos foram realizados no Laboratório de Microbiologia e Fitopatologia do Instituto de Ciências Agrárias da UFMG em Montes Claros - MG.

\section{Coleta e armazenamento dos frutos}

Os frutos de Dimorphandra mollis Benth. foram coletados em outubro de 2005, na Fazenda da Comunidade de Olhos D'água, município de Montes Claros - MG, que está situada a $16^{\circ} 53^{\prime} 34,2^{\prime \prime} \mathrm{S}$ e a $43^{\circ} 53^{\prime} 22,0^{\prime \prime} \mathrm{W}$ a uma altitude de $956 \mathrm{~m}$. Foram coletados frutos na planta e no solo. Os frutos foram acondicionados em um local seco, arejado, sombreado, em temperatura ambiente. Em Montes
Claros-MG, a temperatura média está em torno de $24,2^{\circ} \mathrm{C}$ (Montes Claros, 2008).

\section{Sanidade das sementes}

As sementes sofreram uma desinfestação superficial com hipoclorito de sódio $2 \%$, durante três minutos. Após a desinfestação, foram lavadas em água destilada esterilizada por três vezes e colocadas para secar a temperatura ambiente e sob condições assépticas em câmara de fluxo laminar.

Seguindo a metodologia descrita por Sales (1992), as sementes foram colocadas em caixas gerbox contendo três folhas de papel de filtro esterilizadas e umedecidas com ágar-água $1 \%(1 \mathrm{~g}$ de ágar em $1000 \mathrm{~mL}$ de água). Cada caixa gerbox recebeu 15 sementes de fava d'anta. As caixas foram colocadas em incubadora BOD (Demanda Biológica de Oxigênio), marca Tecnal / modelo TE - 40I., a uma temperatura constante de $25^{\circ} \mathrm{C}$ e fotoperíodo de 12 horas. Após 7 dias de incubação foi realizada a avaliação da flora fúngica das sementes.

Durante a avaliação, examinou-se cada semente com o auxílio de estereomicroscópio, para verificar a presença de estruturas fúngicas (esporos, corpos de frutificação, hifas especializadas), auxiliando na identificação desses microorganismos. Quando necessário, foram feitas lâminas para observação ao microscópio óptico composto binocular.

O delineamento experimental adotado foi o inteiramente casualizado com 2 tratamentos (sementes coletadas no solo e sementes coletadas na planta), com 10 repetições constituídas de caixas gerbox contendo 15 sementes cada.

\section{Germinação}

O teste para avaliação da germinação das sementes foi realizado de acordo com as Regras de Análises de Sementes (Brasil, 1992). Para acelerar o processo germinativo, as sementes sofreram escarificação, manualmente, com o auxílio de uma lixa de grana 80. A assepsia das sementes foi feita utilizando-se uma solução de hipoclorito de sódio $2 \%$, por três minutos, e em seguida lavadas por três vezes em água destilada estéril (Ferreira, 2001).

As sementes de fava d'anta foram semeadas em caixas gerbox, contendo areia peneirada, lavada e autoclavada à $120^{\circ} \mathrm{C}$, por 2 horas. Posteriormente, foram incubadas a uma temperatura constante de $25^{\circ} \mathrm{C}$ e fotoperíodo de 12 horas.

Segundo a metodologia proposta por Brasil (1992), a umidade do substrato foi padronizada para $60 \%$ da sua capacidade de retenção. Para tanto, foi efetuada pesagem de $500 \mathrm{~g}$ desse material e transferência para filtro de papel, tipo coador de café comercial. Em seguida, adicionou-se uma quantidade de água previamente determinada e aguardaram-se 
aproximadamente 15 minutos, para completa drenagem do excesso de água. Este volume foi então determinado, possibilitando o cálculo por diferença da quantidade de água que ficou retida na areia $(100 \%)$. O substrato foi umedecido utilizando água destilada esterilizada. As sementes foram dispostas entre uma camada uniforme de areia e cobertas com cerca de $1 \mathrm{~cm}$ de areia solta (disposição "entre areia").

Para a determinação da porcentagem de germinação, foi contado o número de sementes que, no momento da avaliação, 17 dias após a semeadura, tinham germinado. Considerou-se como germinadas apenas as plântulas normais (Brasil, 1992).

Foram consideradas normais aquelas plântulas que apresentaram todas as suas estruturas essenciais (raiz primária, coleto, epicótilo cotilédones, protófilo ou folíolo) bem desenvolvidas, completas, proporcionais e sadias. Plântulas que apresentaram pequenos defeitos, mas que mostraram desenvolvimento satisfatório e equilibrado foram classificadas como normais. Plântulas anormais foram as que apresentaram qualquer uma das estruturas essenciais ausentes ou muito danificadas e também doentes ou muito deterioradas. Foram consideradas mortas aquelas plântulas que, ao final do teste de germinação, não germinaram, seja por questões fisiológicas, seja por questão de ataque de microorganismos.

O delineamento experimental utilizado foi o inteiramente casualizado com dois tratamentos (sementes coletadas no solo e sementes coletadas na planta), com 10 repetições contendo 15 sementes cada.

\section{Vigor}

O teste para avaliação do vigor das sementes foi realizado de acordo com as Regras de Análises de Sementes (Brasil, 1992). O vigor foi determinado pela avaliação da velocidade de germinação.

A velocidade de germinação foi realizada conjuntamente com o teste de germinação. Até o 10을 dia contaram-se, diariamente, as plântulas que iniciaram o processo germinativo. Ao fim do teste, determinou-se o índice de velocidade de germinação pela somatória do número de plântulas germinadas em cada dia, dividida pelo número de dias decorridos entre a semeadura e a emergência. Dessa forma, o maior índice indica o maior vigor. Para o cálculo foi utilizada a fórmula sugerida por Maguire (1962):

$$
\mathrm{IVG}=\mathrm{G} 1 / \mathrm{N} 1+\mathrm{G} 2 / \mathrm{N} 2+\ldots+\mathrm{Gn} / \mathrm{Nn}
$$

em que IVG é o índice de velocidade de germinação; G1, G2, Gn é o número de plântulas germinadas, computadas na primeira, segunda, até a última contagem; N1, N2, Nn é o número de dias da semeadura à primeira, segunda até a última contagem.

O vigor das sementes foi ainda determinado pela avaliação do desenvolvimento das plântulas. Para isso, determinou-se a massa seca das raízes primárias das plântulas consideradas normais. As raízes foram acondicionadas em sacos de papel e secas em estufa com circulação de ar à temperatura de $40^{\circ} \mathrm{C}$, durante 72 horas, atingindo massa constante. Os resultados também foram expressos em massa média por plântula.

$\mathrm{O}$ delineamento experimental utilizado foi o inteiramente casualizado com dois tratamentos (sementes coletadas no solo e sementes coletadas na planta), com 10 repetições contendo 15 sementes cada.

Todos os dados obtidos foram analisados pelo programa estatístico SAS (Statistical Analysis System) e submetidos à análise de variância, sendo as médias comparadas pelo teste de Tukey a $5 \%$ de probabilidade.

\section{RESULTADOE DISCUSSÃO}

\section{Sanidade das sementes}

Na avaliação sanitária das sementes de fava d'anta detectou-se espécies de 12 fungos. Os fungos identificados e as respectivas ocorrências encontramse na Tabela 1. Independente da forma de coleta das sementes, no geral, os fungos Cladosporium sp. e Fusarium sp. foram os que mais ocorreram nas sementes analisadas.

Para as sementes coletadas no solo, Fusarium sp. (16\%) foi o fungo de maior ocorrência, seguido do fungo Cladosporium sp. (15,3\%). Já para as sementes coletadas na árvore, Cladosporium sp. $(8,7 \%)$ foi o fungo de maior ocorrência, seguido pelos fungos Fusarium sp. (4,7\%) e Penicillium sp. (4,7\%).

$\mathrm{Na}$ literatura, são raras as citações sobre a incidência do fungo Cladosporium em sementes de espécies florestais. Nascimento (2006) detectou Cladosporium sp. como sendo um dos mais freqüentes fungos nas sementes de Pterogyne nitens (amendoim-bravo), juntamente com Aspergillus sp. e Penicillium sp.. Faiad et al. (1997), relataram a ocorrência de $61 \%$ de incidência deste fungo nas sementes de imburama (Commiphora lepthophloeos). Sabe-se que, Cladosporium sp. é patógeno de espécies agrícolas, causando doenças de grande importância econômica como a verrugose do maracujá (Zambolim et al., 2002) e a sarna das curcubitáceas causada por Cladosporium cucumerinum (Rodrigues, 2002).

Fusarium é um gênero que possui diversas 
TABELA 1. Ocorrência de fungos (\%) associados às sementes de frutos de Dimorphandra mollis coletados no solo e na planta.

\begin{tabular}{lcc}
\hline \multicolumn{1}{c}{ Fungos } & $\begin{array}{c}\text { Sementes } \\
\text { no solo }\end{array}$ & $\begin{array}{c}\text { Sementes } \\
\text { na planta }\end{array}$ \\
\hline Alternaria alternata & 0,0 & 0,7 \\
Aspergillus sp. & 0,0 & 1,3 \\
Aspergillus niger & 1,3 & 0,0 \\
Cladosporium sp. & 15,3 & 8,7 \\
Colletrotrichum sp. & 1,3 & 0,0 \\
Fusarium sp. & 16,0 & 4,7 \\
Helminthosporium sp. & 0,0 & 2,0 \\
Nigrospora sp. & 0,7 & 0,0 \\
Penicillum sp. & 6,0 & 4,7 \\
Phoma sp. & 0,7 & 0,0 \\
Phomopsis sp. & 2,0 & 1,3 \\
Fungo desconhecido & 4,0 & 0,7 \\
\hline Total por tratamento & $\mathbf{4 7 , 3} \mathrm{a}$ & $\mathbf{2 4 , 1} \mathrm{b}$ \\
\hline
\end{tabular}

* Médias seguidas da mesma letra na coluna não diferem entre si, pelo teste de Tukey (5\%)

espécies com uma ampla ocorrência em espécies florestais. É um fungo de solo, por isso a sua maior freqüência nas sementes coletadas no chão. Causa, principalmente, tombamento de plântulas, apodrecimento de raízes e apodrecimento de estacas (Ferreira, 1989).

Observando a Tabela 1, a incidência de Fusarium sp. foi superior em sementes provenientes de frutos coletados no solo. O fungo Fusarium spp. sobrevive em restos culturais infectados no solo, sendo uma das principais formas de disseminação (Kimati, 1997). Apesar de ser considerado patógeno de solo (Ethur, 2008) foi observada ocorrência em $4,7 \%$ das sementes provenientes de frutos coletados na planta. Esse fato pode ser explicado por Machado et al. (2000). De acordo com esses autores, as associações com fungos do gênero Fusarium podem ocorrer durante a formação ou maturação do fruto, sendo que cuidados na colheita e no manuseio podem reduzir a contaminação por Fusarium sp.

Sales (1994), testando a patogenicidade de Fusarium, verificou redução da germinação das sementes de ipê amarelo e o apodrecimento das sementes de barbatimão.

Observou-se também a incidência dos fungos Alternaria alternata, Aspergillus sp., Aspergillus niger, Colletrotrichum sp., Helminthosporium sp., Nigrospora sp., Penicillum sp., Phoma sp e Phomopsis sp. nas sementes da fava d'anta. Estes fungos, apesar de se apresentarem com menor freqüência, são importantes patógenos de plantas. Helminthosporium, Colletotrichum, Phoma e Phomopsis causam doenças em diversas espécies cultivadas e também em espécies florestais (Ferreira, 1989; Kimati, 1997). Aspergillus spp., Nigrospora, Penicillium e Alternaria alternata são relatados como prejudiciais à germinação das sementes e desenvolvimento de plântulas (Sales,1994).

Mittal (1983) confirmou a patogenicidade dos fungos Fusarium spp. e Aspergillus niger. Esses fungos prejudicaram a germinação e impediram consideravelmente o desenvolvimento das plântulas de Cedrus deodara. Mittal \& Wang (1986) constataram a redução da germinação das sementes e o mau desenvolvimento das plântulas de Eucalyptus (híbrido) causado pela incidência de Aspergillus niger.

Aspergillus niger, A. flavus, Helminthosporium sp., Penicillium sp., Phoma hibernica causam danos de pré-emergência em espécies de Pinus. Fusarium spp., por sua vez, causam dano de pós-emergência (Munjal \& Sharma, 1976).

Fungos como Colletotrichum dematium (Pers. Ex Fr.) Grove var. truncata (Schw.) Arx. e Phomopsis sojae podem afetar plantas, vagens e sementes em vários estádios da lavoura de soja (Costa, 2003). A baixa germinação das sementes de soja é, na maioria das vezes, causada pela infestação desses fungos (Athow \& Laviolette, 1973).

Sales (1994) constatou que os fungos Alternaria alternata, Fusarium sp., Phoma sp., Phomopsis sp. afetam a germinação e o desenvolvimento das plântulas de ipê-amarelo (Tabebuia serratifolia) e que Phomopsis sp. causou redução da germinação de sementes de barbatimão (Strphnodendron adstringens). Apesar de ter ocorrido germinação das sementes de barbatimão contaminadas com os fungos Fusarium sp. e Phomopsis sp., estas não apresentaram desenvolvimento satisfatório de plântulas devido ao apodrecimento completo dos cotilédones e da radícula. Assim, o fungo Phomopsis sp. promoveu tombamento de pré e pós-emergência reduzindo a germinação das sementes e impedindo a formação de plântulas.

Em geral, as sementes provenientes de frutos coletados no solo apresentaram maior ocorrência dos fungos do que as sementes provenientes de frutos coletados na planta (Tabela 1). Esse fato era de se esperar, já que no solo existe uma maior fonte de inóculo do que na parte aérea das plantas. No solo os fungos conseguem sobreviver por grandes períodos de tempo por meio das suas estruturas de resistência, e estão aptos a voltar à sua atividade assim que entrarem em contato com os frutos e as sementes. Na parte aérea é necessária a ação do vento, da chuva, e de outros agentes de disseminação para que os frutos e sementes se contaminem. 
TABELA 2. Porcentagem de germinação, plântulas normais, anormais e mortas provenientes de sementes de frutos de Dimorphandra mollis coletados no solo e na planta.

\begin{tabular}{lcrrr}
\hline Tipo de coleta & $\begin{array}{c}\text { Germinação } \\
(\%)\end{array}$ & $\begin{array}{c}\text { Plântulas normais } \\
(\%)\end{array}$ & $\begin{array}{c}\text { Plântulas anormais } \\
(\%)\end{array}$ & $\begin{array}{c}\text { Sementes mortas } \\
(\%)\end{array}$ \\
\hline Sementes no solo & $56,67 \mathrm{~b}$ & $56,67 \mathrm{~b}$ & $28,67 \mathrm{a}$ & $14,66 \mathrm{a}$ \\
Sementes na planta & $85,93 \mathrm{a}$ & $85,92 \mathrm{a}$ & $10,37 \mathrm{~b}$ & $3,70 \mathrm{~b}$ \\
\hline
\end{tabular}

* Médias seguidas da mesma letra na coluna não diferem entre si, pelo teste de Tukey (5\%)

\section{Germinação}

As sementes provenientes de frutos coletados na planta apresentaram maior porcentagem de germinação (Tabela 2). Isso pode ser relacionado com a menor ocorrência de fungos nessas sementes. É possível verificar a classificação das plântulas em normal, anormal e em sementes mortas, que infere sobre o vigor das plântulas. Observando-se os valores, nota-se que as sementes coletadas na planta deram origem a uma quantidade superior de plântulas normais. Enquanto que, as sementes provenientes de frutos coletados no solo deram origem a uma maior porcentagem de plântulas anormais e sementes mortas. Como discutido anteriormente, a ação dos fungos afeta a germinação e o desenvolvimento das plântulas, portanto esse resultado é coerente uma vez que as sementes coletadas no solo apresentaram uma maior incidência de fungos e também uma baixa germinação.

\section{Vigor}

Não houve diferença estatística na massa seca das raízes primárias das plântulas provenientes de sementes coletadas no solo e na planta (Tabela 3). Nota-se que, o Índice de Velocidade de Germinação (IVG), assim como nas demais características mencionadas anteriormente (germinação e plântulas normais), foi maior nas sementes de frutos coletados na planta do que nas sementes de frutos coletados no solo. Portanto tais plântulas foram mais vigorosas.

Assim, nas condições em que foi realizado o presente trabalho, foi possível concluir que:

-As sementes de fava d'anta analisadas apresentam flora fúngica diversificada, sendo esses fungos potencialmente patogênicos.

-Os fungos Fusarium sp. e Cladosporium sp. foram os que apresentaram maior ocorrência.

-A incidência de fungos foi mais intensa nas sementes provenientes de frutos coletados no solo do que em sementes provenientes de frutos coletados na planta.

Sementes oriundas de frutos coletados na planta são menos contaminadas por agentes patogênicos possuindo germinação, vigor e sanidade superiores àquelas obtidas de frutos coletadas no solo.
TABELA 3. Vigor (Massa seca das raízes primárias das plântulas e Índice de Velocidade de Germinação) de sementes de frutos de Dimorphandra mollis coletados no solo e na planta.

\begin{tabular}{c|r|l}
\hline Tipo de coleta & Massa seca $(\mathbf{m g})$ & \multicolumn{1}{l}{ IVG } \\
\hline Sementes no solo & $13,75 \mathrm{a}$ & $6,00 \mathrm{~b}$ \\
Sementes na planta & $14,60 \mathrm{a}$ & $6,83 \mathrm{a}$ \\
\hline
\end{tabular}

* Médias seguidas da mesma letra na coluna não diferem entre si, pelo teste de Tukey $(5 \%)$

\section{REFERÊNCIA}

ATHOW, H.L.; LAVIOLETTE, F.A. Pod protection effect on soybean seed germination and infection with Diaporte phaseolorum var. sojae and other microoganisms. Phytopathology, v.63, n.8, p.1021-3, 1973.

BRASIL. Ministério da Agricultura. Regras para análise de sementes. Brasília: Ministério da Agricultura, 1992. $365 \mathrm{p}$.

COSTA, N.P. et al. Qualidade fisiológica, física e sanitária de sementes de soja produzidas no Brasil. Revista Brasileira de Sementes, v.25, n.1, p.128-32, 2003.

ETHUR, L.Z. et al. Presença dos gêneros Trichoderma e Fusarium em solo rizosférico e não rizosférico cultivado com tomateiro e pepineiro, em horta e estufa. Ciência Rural, v.38, n.1, p.19-6, 2008.

FAIAD, M.G.R. et al. Efeito do hipoclorito de sódio sobre a qualidade fisiológica e sanitária de sementes de Commiphora lepthophloeos (Mart.) J.B. Gillet. Revista Brasileira de Sementes, v.19, n.1, p.14-7,1997. FERREIRA, F.A. Patologia florestal: principais doenças florestais no Brasil. Viçosa: Sociedade de Investigações Florestais, 1989. 570p.

FERREIRA, R.A. et al. Morfologia de frutos, sementes, plântulas e plantas jovens de Dimorphandra mollis Benth. - faveira (Leguminosae - Caesalpinioideae). Revista Brasileira de Botânica, v.24, n.3, p.303-9, 2001. GIULIANO, I. et al. Identificação de fungos em sementes de Dimorphandra mollis e efeito de diferentes tratamentos. Fitopatologia Brasileira, v.30, n.5, p.553, 2005.

KIMATI, H. et al. Manual de Fitopatologia: doenças das plantas cultivadas. 3.ed. São Paulo: Agronômica Ceres, 1997. v.2. 774p

LORENZI, H.; MATOS, F.J.A. Plantas medicinais do Brasil: nativas e exóticas cultivadas. Nova Odessa: Instituto 
Plantarum, 2002. 512p.

MACHADO, J.C. Tratamento de sementes no controle de doenças. Lavras: LAPS/UFLA/FAEPE, 2000. 138p. MAGUIRE, J.D. Speed of germination and seedling emergence and vigor. Crop Science, v.2, n.2, p.176-7, 1962.

MITTAL, R.K. Studies on the mycoflora and its control on the seeds of some Forest trees: I Cedrus deodora. Journal of Botany, v.61, p.197-201, 1983.

MITTAL, R.K.; WANG, B.S.P. Emergence failure and top decay in white spruce germinants due to three fungi. Canadian Plant Disease Survey, v.66, n.1, p.5-7, 1986. MONTES CLAROS. Secretaria Municipal de Desenvolvimento Econômico. Dados gerais. Disponível em: <http://www.montesclaros.mg.gov.br>. Acesso em: 27 set. 2008.

MUNJAL, R.L.; SHARMA, A.D. Control of seed mycoflora of some important conifers. Indian Journal of Mycology and Plant Pathology, v.6, p.135-9, 1976.

NASCIMENTO, W.M.O. et al. Qualidade sanitária e germinação de sementes de Pterogyne nitens Tull.
(Leguminosae - Caesalpinioideae). Revista Brasileira de Sementes, v.28, n.1, p.149-53, 2006.

RODRIGUES, A.A.C.; MENEZES, M. Detecção de fungos endofíticos em sementes de caupi provenientes de Serra Talhada e de Caruaru, Estado de Pernambuco, Brasil. Fitopatologia Brasileira, v.27, n.5, p.532-7, 2002.

SALES, N.L.P. Efeito da população fúngica e do tratamento químico no desempenho de sementes de ipê-amarelo, ipê-roxo e barbatimão. 1992. 89p. Dissertação (Mestrado em Fitossanidade) Universidade Federal de Lavras, Lavras.

SALES, N.L.P. Efeito da população fúngica sobre a germinação das sementes e do desenvolvimento de ipê-amarelo (Tabebuia serrratifolia) e barbatimão (Stryphnodendron adstringens). Ciência e Prática, v.18, n.1, p.83-9, 1994.

SILVA, M.F. Dimorphandra (Caesalpiniaceae). Flora Neotropica. New York: Botanical Garden, 1986. p.126.

ZAMBOLIM, L. et al. Controle de doenças de plantas: fruteiras. Viçosa: UFV, 2002. v.1. 674p. 